\title{
Understanding rural restructuring in China: The impact of changes in labor and capital productivity on domestic agricultural production and trade
}

\author{
Qian Zhang ${ }^{\text {a }}$, Zhongxiao Sun ${ }^{\mathrm{b}}$, Feng Wu ${ }^{\mathrm{a}}$, Xiangzheng Deng ${ }^{\mathrm{a},{ }^{*}}$ \\ ${ }^{a}$ Center for Chinese Agricultural Policy, Institute of Geographic Sciences and Natural Resources Research, Chinese Academy of Sciences, Beijing 100101, \\ China \\ b School of Environment, Beijing Normal University, Beijing 100875, China
}

\section{A R T I C L E I N F O}

\section{Article history:}

Received 30 October 2015

Received in revised form

23 April 2016

Accepted 4 May 2016

Available online 28 May 2016

\section{Keywords:}

Labor productivity

Capital productivity

Domestic trade

Import and export volume

TERM

\begin{abstract}
A B S T R A C T
In China, the provinces of Shandong and Henan are the leading provinces for grain production and also have the highest populations. In this study, we quantitatively analyze the impact of the two primary factors that indicate rural restructuring (namely, an increase in labor- and capital-augmenting technical change, represented by labor and capital productivity) on wheat production in Shandong and Henan provinces, and the consequent effects on exported and imported wheat volumes in other provinces through to 2020. For the analysis, we use The Enormous Regional Model (TERM), an established multiregion computable general equilibrium model. The results show that the magnitude of change generated by the increase in labor productivity is larger than that generated by the increase in capital productivity. Therefore, great importance should be attached not only to increasing capital technical change but also improving labor technical change. This study also reveals that regional competitive industry can easily shape absolute competition superiority, which consequently exerts a large impact on the homogeneity of products. Rural China is moving into a critical stage of restructuring, and therefore the government should provide rational top-down guidance. The central government should avoid adopting a "one size fits all" policy and simply supporting a single industry or particular development patterns. Rural China should form stable, sustainable, and specialized agricultural production arranged by geographic areas, which would not only guarantee China's food security, but also improve the nation's competitive capacity in the international market.
\end{abstract}

() 2016 Elsevier Ltd. All rights reserved.

\section{Introduction}

Rural China has been undergoing restructuring because the nation's rapid economic development has accelerated the transformation of agricultural development pathways from extensive to intensive means in rural areas, given the diminishing marginal returns for Chinese agriculture (Li et al., 2015; Long and Woods, 2011; Long, 2014). The rapid economic growth has been driven mainly by a reallocation of labor between labor-intensive and capital-intensive sectors of the economy (Song et al., 2011). Agriculture is a typical labor-intensive sector; however, the migration of farmers to industry or service sectors has contributed greatly to development in China in the past several decades (Liu et al., 2013b;

\footnotetext{
* Corresponding author.

E-mail address: dengxz.ccap@igsnrr.ac.cn (X. Deng).
}

Long and Woods, 2011), with the huge population shift essentially guaranteeing the unprecedented rate of economic growth observed during the last 35 years. The wide disparities in income, social welfare, habits, and customs between rural and urban areas have encouraged rural labor to move to the cities (De Brauw et al., 2002; Liu et al., 2013a). This migration has caused heavier burdens to be placed on the elderly and children, who have disproportionately remained in rural areas (Chang et al., 2011); this in turn may have an influence on food security, because the decrease in the amount of available labor will result in a decrease in total grain production volume. However, training farmers, namely, improving laboraugmenting technical change, will reduce the cost of production and protect the environment (Huang et al., 2012), and may also mitigate the risk of food insecurity.

Capital is another important factor for agricultural production. Since 2004, the direct effect of agricultural capital on production in China has increased (Tao and Zhang, 2013). Agricultural investment 
possesses the characteristics of low profitability and high risk, and Chinese agricultural capital underwent the predicament of scarcity and low accumulation for a long period (Xue, 2012). Because the Chinese central government has always attached great importance to agriculture, the government has invested in agriculture directly, and, in accordance, this policy of support has attracted capital from the market to agricultural production. These measures implemented by the Chinese central government helped agricultural production to accumulate capital effectively, with an annual growth rate of 10\% between 2000 and 2010 (Luo, 2013). The future development of China's agriculture will depend on technical changes rather than just on an increase in the quantity of input of primary factors, such as labor and capital. In short, labor- and capital-augmenting technical change will continue to be important to agricultural production in the future, and it is imperative that these two resources are used effectively if issues such as food production and food security are to be properly addressed.

In studies of the agricultural economy, labor- and capitalaugmenting technical change are usually measured and represented by labor and capital productivity, respectively (Acemoglu, 2000). Several studies have investigated the improvement in and influential factors of agricultural labor and capital productivity (Chen et al., 2012; Li et al., 2012; Tao and Zhang, 2013). However, there have been few studies of the impact of grain production in the large grain-producing provinces of China on other provinces, including with particular respect to the effects of labor- and capitalaugmenting technical change on grain production, import and export volumes. Therefore, in this paper, we use a multi-region general equilibrium model with a scenario design method to analyze the impact of labor- and capital-augmenting technical change (represented by labor productivity and capital productivity) on grain (wheat) production and export volume in Shandong and Henan, and the consequent effects on other provinces in terms of domestic exported and imported volumes of wheat. Shandong and Henan provinces were chosen because they are the largest and second-largest grain-producing provinces in China, respectively.

The combined grain production of Shandong and Henan accounted for almost $18 \%$ of the national total, which is approximate $6 \times 10^{9}$ tons in 2014 (NBSC, 2014). Furthermore, in 2014 these two provinces accounted for almost half of the nation's wheat production (NBSC, 2014). In addition, there are almost 200 million people living in Shandong and Henan provinces, together representing about one-sixth of China's population (NBSC, 2014). Guaranteeing food security in Shandong and Henan provinces is therefore very important for China (Lin et al., 2013). As such, there is a need to study the effects of labor- and capital-augmenting technical change on wheat production in Shandong and Henan provinces and the further effects on other provinces with respect to domestic wheat export and import. The results should inform the creation of policy options for structural adjustments in China's agricultural production.

The remainder of the paper is organized into three sections. Section 2 describes data collation and the theory of the model, as well as the design of four scenarios to analyze the effect of laboraugmenting technical change and capital-augmenting technical change on wheat production in Shandong and Henan. Section 3 presents the results of the simulations and interpretations with respect to the agricultural economy and food security. Section 4 provides concluding remarks.

\section{Data and methodology}

\subsection{General framework}

First, we collected and collated statistical yearbook data and input-output data to construct a database for The Enormous Regional Model (TERM), including data for the 31 provinces and municipalities of the mainland, based on China's IO table of 135 sectors of economic activity for 2007. Second, as the study focused on agriculture, we examined agriculture in detail by splitting it into 22 sectors, ${ }^{1}$ and aggregated manufacture sectors into a single sector and service sectors into a single sector. In this paper, grain production means wheat production because wheat is the dominant grain in these two provinces. Third, we set up four scenarios using TERM to analyze the effects of changes in labor and capital productivity in Shandong and Henan on the production of wheat in Shandong province and Henan province, as well as the amount of change in net export volume from Shandong province and Henan province to the remaining provinces and municipalities by the year 2020. In this paper, "export" and "import" refer to trade in the domestic market, namely, the trade among 31 provinces and municipalities in China.

The first scenario was a "business as usual" (BAU) scenario following the trend of previous years, with an increase in laboraugmenting technical change in both provinces and an increase in capital-augmenting technical change in Shandong province and a decrease in Henan province, as expected. The second scenario was an increase in capital-augmenting technical change for wheat production in both Shandong and Henan. The third scenario was an increase in labor-augmenting technical change for wheat production in both Shandong and Henan. The fourth scenario was the combination of the second and the third scenarios (i.e., an increase in both capital- and labor-augmenting technical change). The analysis focuses on discovering the value difference between the BAU scenario and the other three scenarios, and is able to show how a single variable affects the whole system, which is one of the advantages of using TERM. This analysis reveals both the separate and combined impacts of labor- and capital-augmenting technical change on the production of wheat in both Shandong province and Henan province, as well as the amount of change in net exports from Shandong province and Henan province to other provinces by the year 2020 (Fig. 1).

\subsection{TERM model}

TERM is a representative "bottom-up" multiregional Computable General Equilibrium (CGE) model and is able to analyze the regional impacts transmitted from other regions (Wittwer, 2012; Wittwer and Horridge, 2010). TERM was developed by the Centre of Policy Studies (CoPS), Victoria University, Australia. The theory of TERM is similar to that of the common CGE model, which is a simplified representation of the economic system. The outstanding feature of TERM is its treatment of trade relationships between regions (Horridge et al., 2005). The model simulates the condition that all agents use the primary factors of labor, capital, and land to produce commodities; these commodities are traded among different regional markets and finally consumed by consumers, and the system in the model maintains a dynamic balance between supply and demand. A more detailed description of TERM is available in Horridge et al. (2005). For the present study, we draw attention to the three basic assumptions about trade relationships in TERM: (1) Common proportions, whereby all users in a given

\footnotetext{
1 These 22 agricultural sectors include 11 farming sectors (soybean, corn, wheat, rice, potato, vegetables, oilseed, apple, grape, cotton and other planting crops), 4 livestock husbandry (pig, cattle, sheep and other livestock), 4 sectors of meat slaughtering and processing (pork, beef, mutton, and other meat), forestry, fishery, and sector of services in support of agriculture. The details on how these 22 agricultural sectors have been generated is presented in Fig. 2 and Section 2.3 .
} 


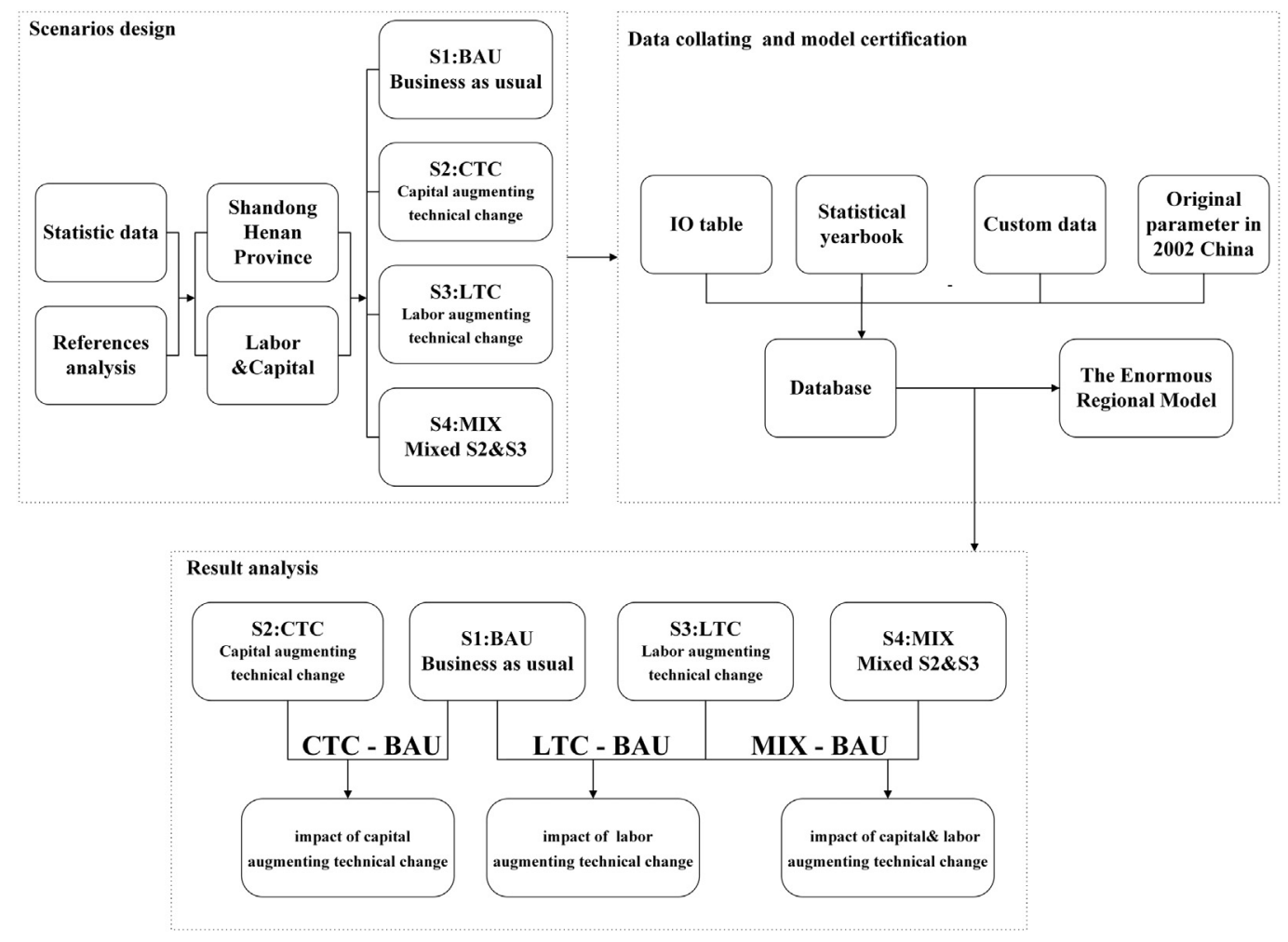

Fig. 1. The framework used in this study.

region source the same commodities from other regions in accordance with common proportions; (2) Common source, whereby all users of a particular good in a particular region possess the same source mixture; and (3) price competitiveness of freight services, whereby the same transportation cost is used whatever commodity is transported (Horridge and Wittwer, 2008). GEMPACK software was used for the model calculations, and equations were linearized through differentiation. The output values of variables are generally in percentage form.

\subsection{Generating the TERM database}

For this study of regions in China, we constructed a database to be analyzed using TERM based on China's 135-sector input-output table for 2007 as well as various parameters of elasticity referred to in the database of China for 2002 (Horridge and Wittwer, 2008).

The procedure for generating the TERM database comprised three stages (Fig. 2). The first stage involved collating and checking the initial input data, using the biproportional scaling method (RAS) to check the balance between input and output. The second and most important stage was building the bottom-up database. Stage 2 included three steps, which are described in the next few paragraphs within this section in detail. The third stage involved checking and aggregating regions and sectors. In this stage, we aggregated industries into a single sector and tertiary industries into a single sector, but divided the agriculture sector into 22 sectors to provide more detail. Therefore, the database contained 24 sectors covering 31 provinces and municipalities of mainland China.

The first step of Stage 2 was to split the column of the national input-output table using the share of production and final demand through 31 provinces and municipalities into categories of the share of output (R001), the share of investment (R002), the share of urban and rural consumption (R003), the share of exports in port (R004), the share of government demand (R005), and share of imports in

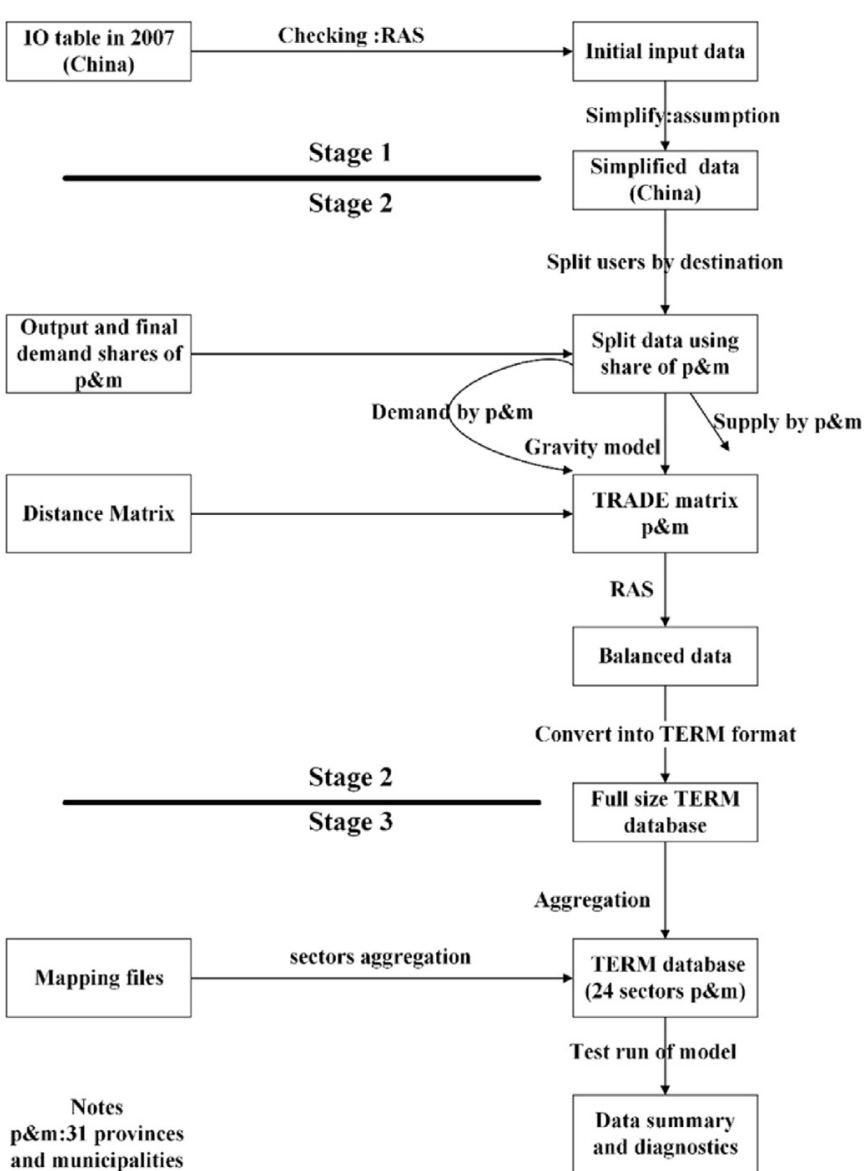

Fig. 2. The three stages of constructing the TERM database used in this study. 
port (MSHR), as described below. The demand and supply of imported and domestic goods for 31 provinces and municipalities was then deduced, following which the trade matrix was constructed.

Specifically, to calculate $R 001$ in 31 provinces and municipalities, we required multiple-source datasets. For the sectors of wheat, cotton, vegetables, forest, fishing, pigs, cattle, and sheep, the statistical values of output in the China Agriculture Yearbook were used to represent the respective shares of output value (MAC, 2008). For the sectors of corn, rice, soybean, potato, oilseed, apple, grape, pork, mutton, and beef, the values of quantity of output in the China rural statistical yearbook (NBSC, 2008a) and the prices in China Yearbook of Agriculture Price Survey (NBSC, 2008c) and National Agricultural Products Data Compilation of Cost and Benefit (NBSC, 2008d) were used to represent the respective shares of output value. We used the product of price and quantity as the output value, and then calculated the respective shares of output value of each goods sector in 31 provinces and municipalities. In cases where there was no statistical price of goods in some provinces or municipalities, we used the national average price instead. According to the national input-output survey scheme in 2007, we mapped manufacture and service sectors in 135 sectors of the national input-output table into 42 sectors of the national input-output table. Because there is no input-output table for Tibet, we used the share of TERM database in 2002 for that region, and then used the value as found in the national input-output table to multiply the share to obtain the value for R001 needed for making the database. This same procedure was used for R002, R002, R004, and R005. Then, we used the values of output in the 42 sectors of the input-output table for 31 provinces and municipalities to calculate the share of output in these provinces and municipalities. To calculate R002 in those provinces and municipalities, we used the value of investment in the 42 sectors of the input-output table for 31 provinces and municipalities. For agricultural sectors, we assumed that all 20 agricultural sectors had the same share. To calculate R003, more detailed statistics are available for consumer goods under eight categories of urban consumption in the China Statistical Yearbook (NBSC, 2008b). For the purpose of this study, we used the method of approximate replacement for urban consumption, as follows. For the soybean sector, we used the share of beans and their products. For wheat, rice, corn, and other crops, we used the share of grain. For the potato sector, we used starches and tubers. For the vegetables sector, we used vegetables. For the oilseed sector, we used oil or fat. For the apple, grape, and forest sectors, we used dry and fresh fruit. For pigs, cattle, sheep, other livestock, pork, mutton, beef, and other meat sector, we used meat and poultry. For the fishing sector, we used aquatic products. For the other agricultural products sector, we used other food. For the industry and service sectors, we used the same approach for calculating the shares of output. For rural consumption, we used the share calculated for rural consumption of the 42 sectors in the input-output table for 31 provinces and municipalities, and the shares of all 22 agricultural sectors were the same. R004 and MSHR were calculated using data from the China Customs Statistics Yearbook (GACC, 2008) and China customs port statistics. Finally, we used the same approach as used for calculating the share of investment and rural consumption to calculate R005, namely, the share of government demand.

The second step of Stage 2 was to construct the trade matrix. The trade matrix for TERM was built based on the distance matrix and gravity model. For the local supply share,

$$
\begin{aligned}
\operatorname{OWNSHARE}(c, s, d)= & \operatorname{Min}[1, \operatorname{SuppratiO}(c, s, d)] \\
& \times\left[1-\left(0.2^{\operatorname{DiSTFAC}(c, s)}\right)\right]
\end{aligned}
$$

where

$$
\operatorname{SUPPRATIO}(c, s, d)=\operatorname{ALLSUPPLY}(c, s, d) / \operatorname{ALLDEMAND}(c, s, d)
$$

and where $\operatorname{DISTFAC}(c, s)$ is the distance factor for the gravity formula. Normally, the distance is 1 , and a value of 2 stands for goods that are difficult to transport.

For shares from all other sources, we used

$$
\begin{aligned}
& \operatorname{sOURCESHR}(c, s, r, d)=\left[\operatorname{ALLSUPply}(c, s, r)^{0.5}\right] / \\
& {\left[\operatorname{DiSTANCE}(r, d)^{\operatorname{DiSTFAC}(c, s)}\right] * \operatorname{DEFREG}(c, s, r) * \operatorname{LAMBDA}(c, s, d)}
\end{aligned}
$$

where $\operatorname{LAMBDA}(c, s, d)$ satisfies $r \operatorname{SOURCESHR}(c, s, r, d)=1$, and then $\operatorname{DEFREG}(c, s, r)=0.1$ for regions where $\operatorname{SUPPRATIO}(c, s, r)<1$, and is otherwise 1 .

The third step of stage 2 was to use the RAS method to balance the data.

\subsection{Scenarios}

In classical economics, labor and capital are the primary factors of production, and are particularly important in grain production. Furthermore, the technical change in the use of these primary factors is becoming more important than changes in their quantity (Acemoglu, 2000). Therefore, in this paper, we focus on the effects of technical change in both labor and capital, represented by changes in both labor and capital productivity. Agricultural production is a labor-intensive sector, and the labor force is experiencing restructuring in rural China. Improving labor-augmenting technical change will reduce the cost of producing grain and will increase agricultural revenue (Huang et al., 2012). Therefore, we set up a scenario of an increase in labor-augmenting technical change to analyze the impact of wheat production changes in Shandong and Henan on other regions.

China began to execute a subsidy policy for purchasing agricultural machines in 2004 and abolished agricultural tax ${ }^{2}$ in 2006 (Kennedy, 2007). Subsidies have increased sharply since 2004, which indicates that the distribution of capital between different industries has begun to be restructured. More capital has been migrating to the agricultural sector, and this redistribution of capital has been critical to Chinese agriculture. However, how to use this capital effectively is an important issue for the development of Chinese agriculture in the future. Therefore, we set up a scenario of capital-augmenting technical change to analyze the impact of wheat production changes in Shandong and Henan on other regions.

In TERM, there is an important difference between the identified scenario(s) and the BAU scenario, which is the difference in the value of shock variables. Examples of these variables include the technical change in labor, the technical change in capital, the technical change in the composition of primary factors, the number of households, the quantity of land, and total household consumption. This difference between scenarios should allow the impact of a single variable on the system under study to be investigated (Fig. 3).

When setting up the scenarios of labor technical change (LTC),

\footnotetext{
${ }^{2}$ Agricultural tax was collected before 2006 by China's governments from agricultural production units and individuals who had agricultural income. Generally, agricultural tax base in China was formulated according to yield or income from agricultural products.
} 
capital technical change (CTC), and the mixture of LTC and CTC (MIX), we selected Jiangsu province, the best performer with respect to labor productivity and capital productivity in the North China Plain area, as the target province. This was because Shandong and Henan are also located in this area, meaning that these three provinces have similar natural conditions for wheat production, but labor and capital conditions are different. In other words, we expect the values of labor and capital productivity in Shandong and Henan by 2020 could be promoted to the 2012 level of Jiangsu. We apply the perpetual inventory method to calculate capital stock and then calculate labor and capital productivity. Calculation results for labor and capital productivity are contained in Tables 1 and 2 correspondingly.

The percentage changes in labor and capital productivity for these four scenarios are presented in Table 3. These changes in labor and capital productivity under BAU correspond to the trend recorded from 2004 to 2012.

\section{Results and discussion}

\subsection{Scenario-based simulation results}

Compared to the BAU scenario, capital productivity under the CTC scenario is higher by $89.7 \%$ and $82.1 \%$ in 2020 , but the amount of capital is lower by $56.9 \%$ and $49.6 \%$ in 2020 compared with 2007 in Shandong and Henan provinces, respectively. Ultimately, the wheat yield correspondingly increases by $3.84 \%$ and $4.1 \%$ in Shandong and Henan, respectively. Similarly, labor productivity under the LTC scenario is higher by $26.5 \%$ and $69.7 \%$ in 2020 compared with 2007 in Shandong and Henan, respectively. By 2020, wheat yield increases by $160.9 \%$ in Henan but decreases slightly (by $7.7 \%$ ) in Shandong province. Furthermore, capital and labor productivities are modeled to increase simultaneously under the MIX scenario, in which wheat yield increases by $167.8 \%$ in Henan but decreases by $5.1 \%$ in Shandong.

The results of these simulations suggest that it is more effective to increase labor productivity than to increase capital productivity. The main reason is that wheat production is labor intensive. Moreover, there exists fierce competition between Shandong and Henan province in the production of wheat, because Henan and Shandong are the largest and the second-largest wheat-producing provinces in China. This shock of a substantial increase in wheat yield in Henan province ultimately leads to a decrease in wheat yield in Shandong province. However, caution should be applied in interpreting the decrease in wheat yield in Shandong province, because the yield is driven by both productivity increase and market competition. The increases in the output of wheat in Henan and Shandong under the MIX scenario are slightly higher than the

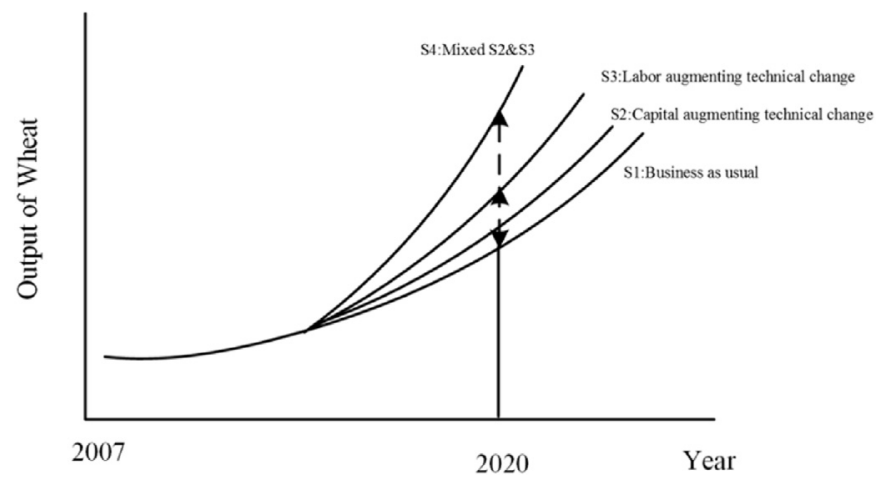

Fig. 3. Sketchmap of the four scenarios (S1-S4) designed in this study. sum of the percentage increases in wheat yield for the CTC and LTC scenarios. The result suggests that increasing both labor- and capital-augmenting technical change simultaneously is slightly more effective than increasing one factor individually.

As indicated by the difference between the CTC and BAU scenarios, the amounts of wheat export and import for Shandong province increase by $7.4 \%$ and decrease by $5.9 \%$, respectively. Similarly, the amounts of wheat exported and imported by Henan province increase by $5.6 \%$ and decrease by $6.2 \%$, respectively. As a result, the net amount of wheat exported increases for both Shandong and Henan. With respect to the increase in the amount of wheat exported from Shandong province (Fig. 4), Shandong itself and Guangdong province are the largest and second-largest provinces, which account for $19.1 \%$ and $8.1 \%$ of the total change in the net exported amount, respectively. However, in Henan, the increase in wheat yield is used mainly for exporting to other provinces, and the amount of change in wheat production in Henan province and used by Henan accounts only for $6.2 \%$ of the total change in the net exported amount. The change in the net exported amount of wheat from Henan province will affect Guangdong most, accounting for $13 \%$ of the total increase in net exports (Fig. 4). The main reason is that the amount of wheat produced in Henan is extremely large, and there is insufficient capability for the province to consume all the wheat that it produces. In addition, the food-processing industry is more advanced in Shandong province compared with Henan province, and therefore Shandong is able to consume the increased wheat yield more effectively. From the spatial perspective of export destination and net exported amount of wheat produced in both Shandong and Henan, the increase in net exported amount is greatest for Guangdong, Zhejiang, and Jiangsu provinces, besides self-consumption in Shandong and Henan provinces. This corroborates the developed status of the food-processing industry or of industries with food as raw materials in these provinces (Liu et al., 2012).

Under the LTC scenario (cf. the BAU scenario), the amount of wheat exported by Henan province increases by $224.6 \%$, and the amount imported by Henan decreases by $96.4 \%$. In contrast, under the LTC scenario (cf. the BAU scenario), the amount of wheat exported by Shandong decreases by $10.8 \%$, and the amount imported by Shandong increases by $45.7 \%$. There are two major reasons for these patterns. First, labor-augmenting technical change in Shandong province increases significantly but less than that in Henan, and consequently the effect of labor productivity increase in Shandong is smaller than in Henan. Second, there exists fierce competition in wheat production between Shandong province and Henan province in the domestic market, and the increased amount of wheat produced in Henan will satisfy the demand of the national domestic market, finally causing the net amount of wheat exported in Shandong province to decrease. Similar to the CTC scenario, the net amount of wheat exported by Henan province to all provinces increases, and Guangdong province is the largest recipient of exported wheat, accounting for $11.8 \%$ of the increase in the net amount of wheat exported by Henan province (Fig. 5). Henan province is the largest wheat producer, and labor-augmenting technical change increases markedly by 2020 , which causes the output of wheat to increase substantially, in turn causing the net amount traded to increase. The situation is different from the CTC scenario, in that the net amount of wheat exported from Shandong province increases in some provinces (labeled in green, Fig. 5) and decreases in other provinces (labeled in red, Fig. 5). Interestingly, except for Henan province, the amount of wheat imported by Shandong province from all other provinces decreases, and therefore the increased amount of import wheat is all exported from Henan province.

Under the MIX scenario (cf. the BAU scenario), the amount of 
Table 1

Calculation results of capital productivity from 2004 to 2012 .

\begin{tabular}{|c|c|c|c|c|c|c|c|c|c|}
\hline & 2004 & 2005 & 2006 & 2007 & 2008 & 2009 & 2010 & 2011 & 2012 \\
\hline China & 6.15 & 6.74 & 7.41 & 7.98 & 8.64 & 9.32 & 10.06 & 11.02 & 11.88 \\
\hline Beijing & 14.19 & 13.94 & 14.46 & 14.64 & 14.30 & 15.16 & 15.11 & 15.84 & 16.86 \\
\hline Tianjin & 12.71 & 13.42 & 14.00 & 14.78 & 15.57 & 16.23 & 16.72 & 18.00 & 19.06 \\
\hline Hebei & 8.27 & 9.05 & 9.75 & 10.39 & 10.90 & 11.30 & 11.80 & 12.56 & 13.18 \\
\hline Shanxi & 4.28 & 4.07 & 4.29 & 4.29 & 4.37 & 4.61 & 4.87 & 5.08 & 5.41 \\
\hline Inner Mongolia & 9.34 & 10.18 & 10.41 & 10.74 & 11.81 & 12.05 & 12.50 & 13.19 & 13.68 \\
\hline Liaoning & 11.07 & 11.93 & 12.86 & 13.57 & 14.53 & 15.05 & 15.78 & 16.90 & 17.89 \\
\hline Jilin & 10.10 & 11.05 & 11.52 & 11.67 & 12.80 & 13.04 & 13.56 & 14.09 & 15.29 \\
\hline Heilongjiang & 7.31 & 8.02 & 8.68 & 9.12 & 9.81 & 10.22 & 11.04 & 11.72 & 12.48 \\
\hline Shanghai & 14.37 & 14.42 & 16.05 & 16.77 & 18.47 & 18.59 & 22.72 & 22.44 & 18.40 \\
\hline Jiangsu & 8.73 & 9.53 & 10.45 & 11.50 & 12.46 & 14.22 & 15.75 & 16.98 & 18.36 \\
\hline Zhejiang & 10.47 & 10.90 & 11.91 & 12.61 & 13.64 & 14.23 & 16.64 & 18.74 & 19.60 \\
\hline Anhui & 5.19 & 5.42 & 5.91 & 6.45 & 7.05 & 7.53 & 7.85 & 8.09 & 8.91 \\
\hline Fujian & 10.87 & 11.81 & 12.39 & 13.43 & 14.32 & 15.21 & 15.76 & 16.18 & 17.00 \\
\hline Jiangxi & 7.32 & 7.79 & 8.31 & 8.58 & 9.10 & 9.63 & 10.06 & 10.70 & 11.58 \\
\hline Shandong & 7.12 & 8.07 & 8.57 & 9.16 & 9.43 & 9.90 & 10.36 & 11.08 & 11.83 \\
\hline Henan & 5.08 & 5.65 & 6.24 & 6.76 & 7.32 & 7.85 & 8.36 & 8.81 & 9.35 \\
\hline Hubei & 6.16 & 6.36 & 6.65 & 6.95 & 7.32 & 7.73 & 8.14 & 8.56 & 9.18 \\
\hline Hunan & 6.23 & 6.72 & 7.26 & 7.76 & 8.28 & 8.83 & 8.33 & 9.67 & 10.03 \\
\hline Guangdong & 8.08 & 8.44 & 8.54 & 8.85 & 9.13 & 9.67 & 10.8 & 11.69 & 12.22 \\
\hline Guangxi & 5.34 & 5.77 & 6.13 & 6.49 & 6.70 & 7.00 & 7.28 & 7.66 & 8.55 \\
\hline Hainan & 13.52 & 14.16 & 15.19 & 16.18 & 17.45 & 18.32 & 19.83 & 20.79 & 21.54 \\
\hline Chongqing & 5.27 & 5.67 & 5.51 & 7.12 & 7.68 & 8.28 & 8.86 & 9.75 & 10.47 \\
\hline Sichuan & 5.70 & 6.07 & 6.56 & 7.00 & 7.45 & 7.87 & 8.52 & 9.07 & 9.73 \\
\hline Guizhou & 2.04 & 2.14 & 2.29 & 2.40 & 2.57 & 3.38 & 3.80 & 3.90 & 4.25 \\
\hline Yunnan & 3.55 & 3.77 & 4.06 & 4.34 & 4.68 & 4.94 & 5.16 & 5.38 & 5.96 \\
\hline Tibet & 5.15 & 5.41 & 5.52 & 5.67 & 5.97 & 5.98 & 6.12 & 6.30 & 6.50 \\
\hline Shaanxi & 4.09 & 4.55 & 4.92 & 5.37 & 5.93 & 6.45 & 7.00 & 7.70 & 8.44 \\
\hline Gansu & 3.22 & 3.43 & 3.61 & 3.75 & 3.96 & 4.06 & 4.28 & 4.56 & 4.96 \\
\hline Qinghai & 4.00 & 4.33 & 4.59 & 5.23 & 5.37 & 5.79 & 6.28 & 6.88 & 7.66 \\
\hline Ningxia & 4.39 & 4.65 & 5.12 & 5.40 & 6.02 & 6.73 & 7.37 & 5.98 & 6.29 \\
\hline Xinjiang & 11.06 & 11.66 & 12.13 & 12.89 & 13.60 & 14.05 & 14.32 & 14.40 & 14.52 \\
\hline
\end{tabular}

Unit: thousand Chinese Yuan per capita at 2004 price.

Table 2

Calculation results of labor productivity from 2004 to 2012.

\begin{tabular}{|c|c|c|c|c|c|c|c|c|c|}
\hline & 2004 & 2005 & 2006 & 2007 & 2008 & 2009 & 2010 & 2011 & 2012 \\
\hline China & 1.15 & 2.12 & 3.21 & 3.92 & 4.03 & 3.41 & 3.07 & 3.02 & 2.79 \\
\hline Beijing & 0.63 & 1.12 & 1.70 & 2.23 & 2.33 & 1.65 & 1.72 & 1.77 & 1.00 \\
\hline Tianjin & 0.84 & 1.55 & 2.45 & 3.31 & 2.76 & 1.69 & 1.38 & 0.99 & 0.78 \\
\hline Hebei & 0.70 & 1.30 & 2.07 & 2.79 & 3.03 & 2.73 & 2.58 & 2.70 & 2.46 \\
\hline Shanxi & 0.92 & 1.57 & 2.29 & 2.39 & 2.40 & 1.60 & 1.16 & 1.16 & 1.01 \\
\hline Inner Mongolia & 0.63 & 1.18 & 1.60 & 1.82 & 1.75 & 1.38 & 1.27 & 1.25 & 1.17 \\
\hline Liaoning & 0.96 & 1.76 & 2.53 & 2.96 & 2.91 & 2.87 & 2.86 & 2.51 & 2.38 \\
\hline Jilin & 0.80 & 1.50 & 2.27 & 2.56 & 2.77 & 2.82 & 2.58 & 2.33 & 2.17 \\
\hline Heilongjiang & 0.67 & 1.19 & 1.73 & 1.99 & 2.10 & 1.74 & 1.63 & 1.44 & 1.37 \\
\hline Shanghai & 0.62 & 1.15 & 1.84 & 3.08 & 4.65 & 5.19 & 4.31 & 4.05 & 5.23 \\
\hline Jiangsu & 3.70 & 6.32 & 8.98 & 10.27 & 10.34 & 8.04 & 6.74 & 6.81 & 6.78 \\
\hline Zhejiang & 1.00 & 1.86 & 3.26 & 4.77 & 6.62 & 6.72 & 6.97 & 6.55 & 5.10 \\
\hline Anhui & 2.05 & 3.47 & 4.73 & 5.48 & 5.23 & 4.54 & 4.47 & 4.50 & 3.82 \\
\hline Fujian & 1.70 & 3.07 & 4.99 & 6.41 & 7.02 & 6.48 & 5.64 & 5.46 & 4.64 \\
\hline Jiangxi & 1.41 & 2.48 & 3.74 & 4.77 & 4.78 & 3.50 & 3.08 & 3.29 & 2.89 \\
\hline Shandong & 0.95 & 1.72 & 2.52 & 3.11 & 3.27 & 3.31 & 3.07 & 2.96 & 2.76 \\
\hline Henan & 1.45 & 2.63 & 3.91 & 4.21 & 3.48 & 2.62 & 2.36 & 2.62 & 2.70 \\
\hline Hubei & 1.93 & 3.50 & 5.17 & 5.88 & 5.67 & 4.48 & 3.97 & 4.10 & 3.41 \\
\hline Hunan & 1.73 & 3.23 & 5.10 & 6.68 & 7.57 & 6.21 & 4.59 & 4.17 & 3.66 \\
\hline Guangdong & 1.38 & 2.84 & 5.11 & 7.11 & 7.66 & 7.56 & 6.17 & 5.08 & 4.59 \\
\hline Guangxi & 2.53 & 4.29 & 5.63 & 5.80 & 5.73 & 4.77 & 4.33 & 3.93 & 3.63 \\
\hline Hainan & 1.69 & 3.06 & 4.82 & 6.25 & 9.13 & 9.45 & 12.29 & 14.71 & 12.60 \\
\hline Chongqing & 1.48 & 2.57 & 3.10 & 3.79 & 3.65 & 2.40 & 1.95 & 1.80 & 1.70 \\
\hline Sichuan & 1.90 & 3.41 & 4.84 & 5.49 & 5.06 & 3.71 & 3.35 & 4.02 & 4.16 \\
\hline Guizhou & 1.59 & 2.97 & 4.91 & 6.66 & 6.58 & 5.18 & 5.01 & 4.77 & 5.20 \\
\hline Yunnan & 1.31 & 2.28 & 3.52 & 4.16 & 3.88 & 3.05 & 2.99 & 3.89 & 4.09 \\
\hline Tibet & 0.93 & 1.36 & 1.67 & 1.76 & 1.89 & 1.56 & 1.47 & 1.47 & 1.50 \\
\hline Shaanxi & 1.04 & 1.94 & 2.74 & 3.42 & 3.38 & 2.39 & 1.93 & 1.63 & 1.42 \\
\hline Gansu & 0.87 & 1.60 & 2.27 & 2.91 & 3.17 & 2.59 & 2.39 & 2.61 & 2.47 \\
\hline Qinghai & 0.41 & 0.81 & 1.22 & 1.50 & 1.68 & 1.32 & 1.03 & 0.96 & 1.09 \\
\hline Ningxia & 0.34 & 0.63 & 0.99 & 1.27 & 1.48 & 1.58 & 1.83 & 1.97 & 1.74 \\
\hline Xinjiang & 0.42 & 0.77 & 1.25 & 1.72 & 2.19 & 2.36 & 2.27 & 2.37 & 2.28 \\
\hline
\end{tabular}

Unit: thousand Chinese Yuan per capita at 2004 price. 
Table 3

Percentage change in shock variables under the four scenarios.

\begin{tabular}{c|c|c|c|c}
\hline \multirow{2}{*}{ Var-Reg } & \multicolumn{2}{|c|}{ Change in labor productivity } & \multicolumn{2}{c}{ Change in capital productivity } \\
\cline { 2 - 5 } & Shandong & Henan & Shandong & Henan \\
\hline BAU & $73.9 \%$ & $101.9 \%$ & $28.3 \%$ & $-21.1 \%$ \\
\hline LTC & $100.4 \%$ & $171.6 \%$ & $28.3 \%$ & $-21.1 \%$ \\
\hline CTC & $73.9 \%$ & $101.9 \%$ & $118.0 \%$ & $61.1 \%$ \\
\hline MIX & $100.4 \%$ & $171.6 \%$ & $118.0 \%$ & $61.1 \%$ \\
\hline
\end{tabular}

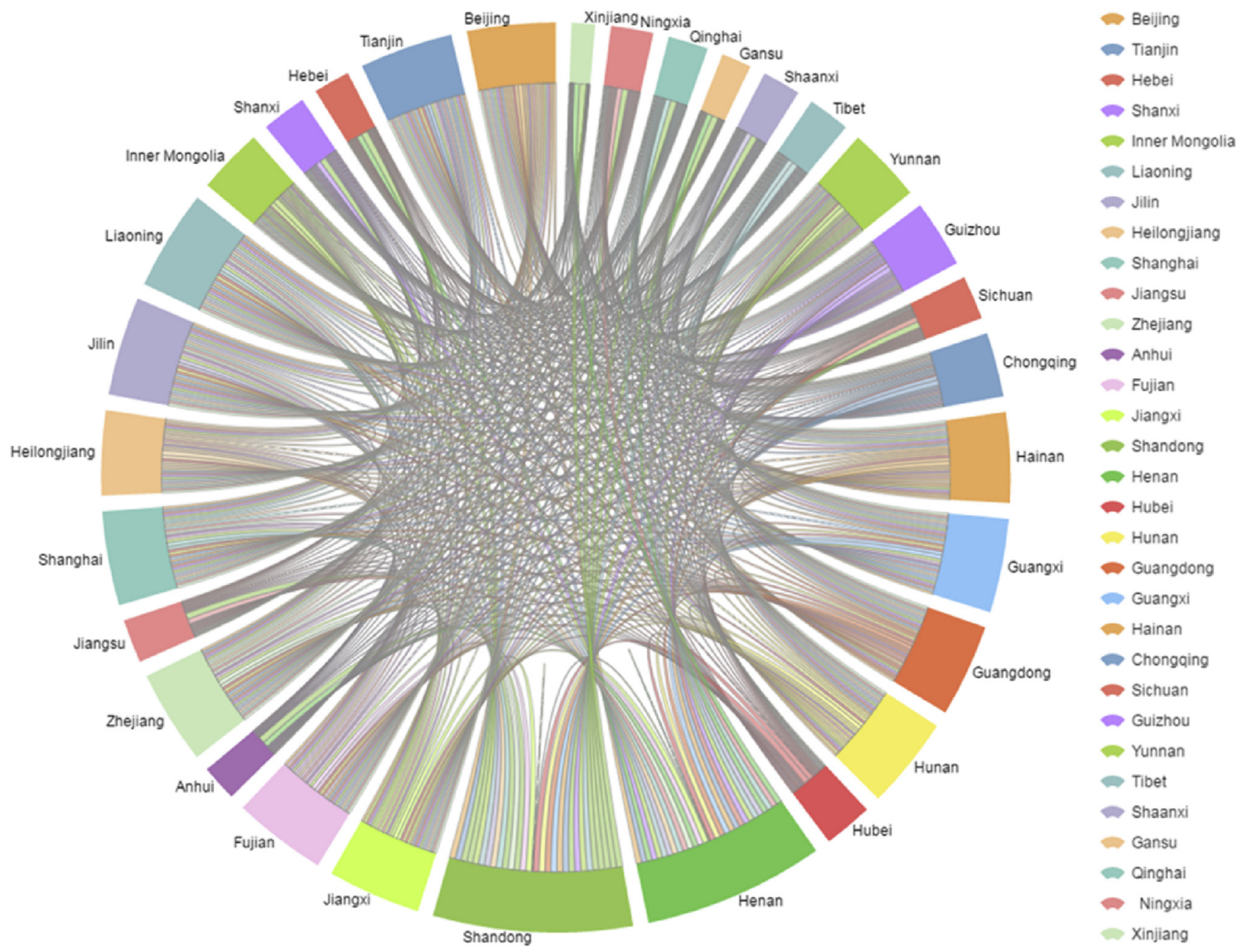

Fig. 4. Changes in the amount of wheat exported from Shandong and Henan provinces to other provinces under the CTC scenario (cf. the BAU scenario).

wheat exported by Shandong decreases by $5.82 \%$ and the amount imported increases by $42.17 \%$. In contrast, the amount of wheat exported by Henan province increases by $234.09 \%$ and the amount imported decreases by $96.97 \%$. The situation is similar to the LTC scenario, in that the net amount of wheat exported from Shandong province increases in some provinces (labeled in green, Fig. 6) and decreases in other provinces (labeled in red, Fig. 6), which suggests a comparative advantage for wheat production for some provinces over others. Similarly, Guangdong is also the largest recipient of wheat exported from Henan province, accounting for $11.78 \%$ of the total net amount of wheat exported by Henan province under the MIX scenario. The results for the MIX scenario show that the change in the amount of wheat exported from Henan province is more than the sum of the changes in the amounts in the LTC and
CTC scenarios. The results also confirm that the increased amount of wheat produced in Henan province is mainly exported to other provinces.

In summary, Shandong and Henan are the two largest wheatproducing provinces. Changes in the productivity of both labor and capital in Shandong and Henan will have an important effect on other regions in terms of wheat import-export volumes, and will have a strong influence on food security in China.

\subsection{Discussion}

Although robust results have been obtained in this study, it should be noted that the model we applied did not apply transportation for mass freight to correct the trade data, nor did it take 


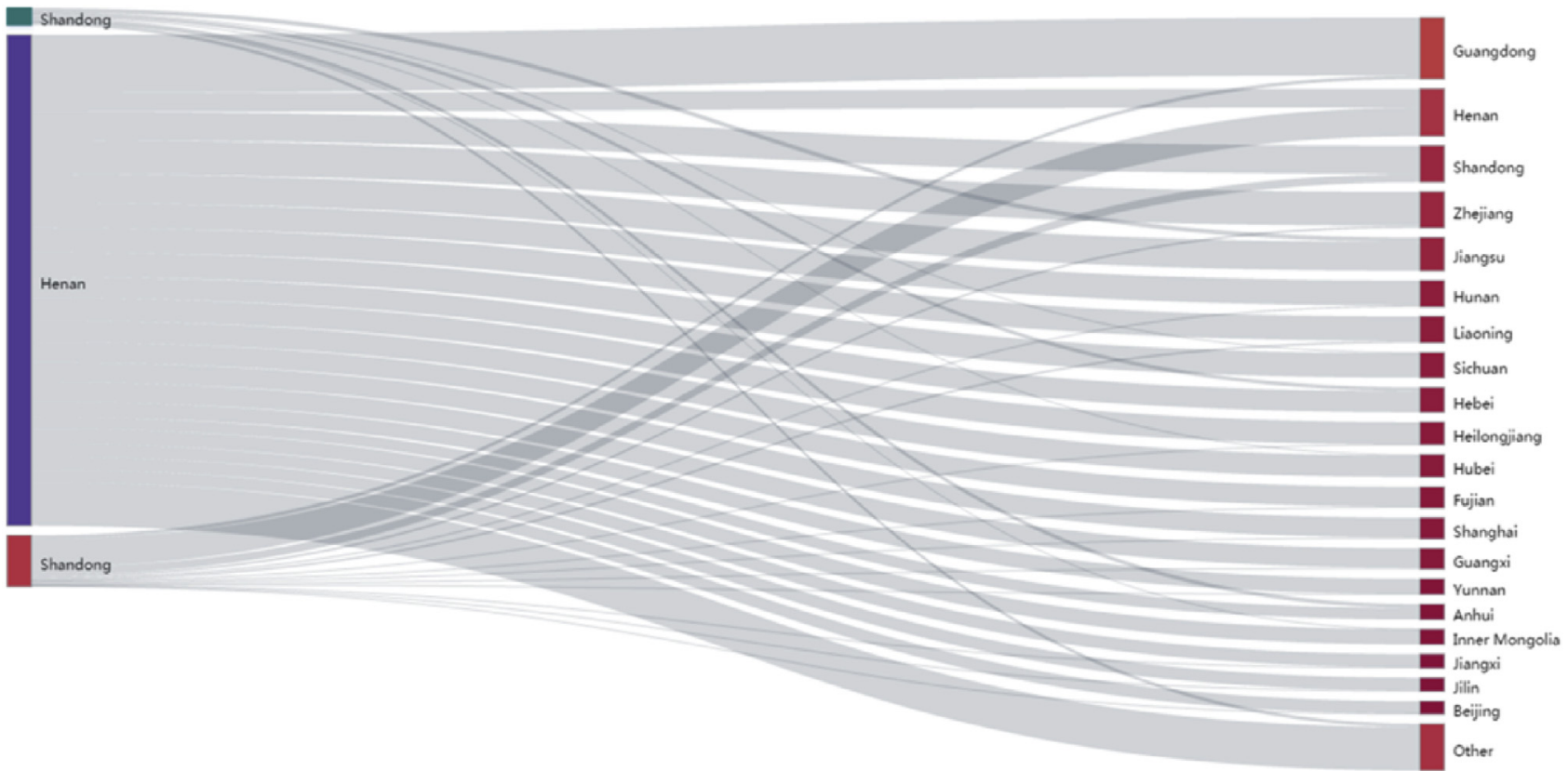

Fig. 5. Changes in the amount of wheat exported from Shandong and Henan provinces to other provinces under the LTC scenario (cf. the BAU scenario).

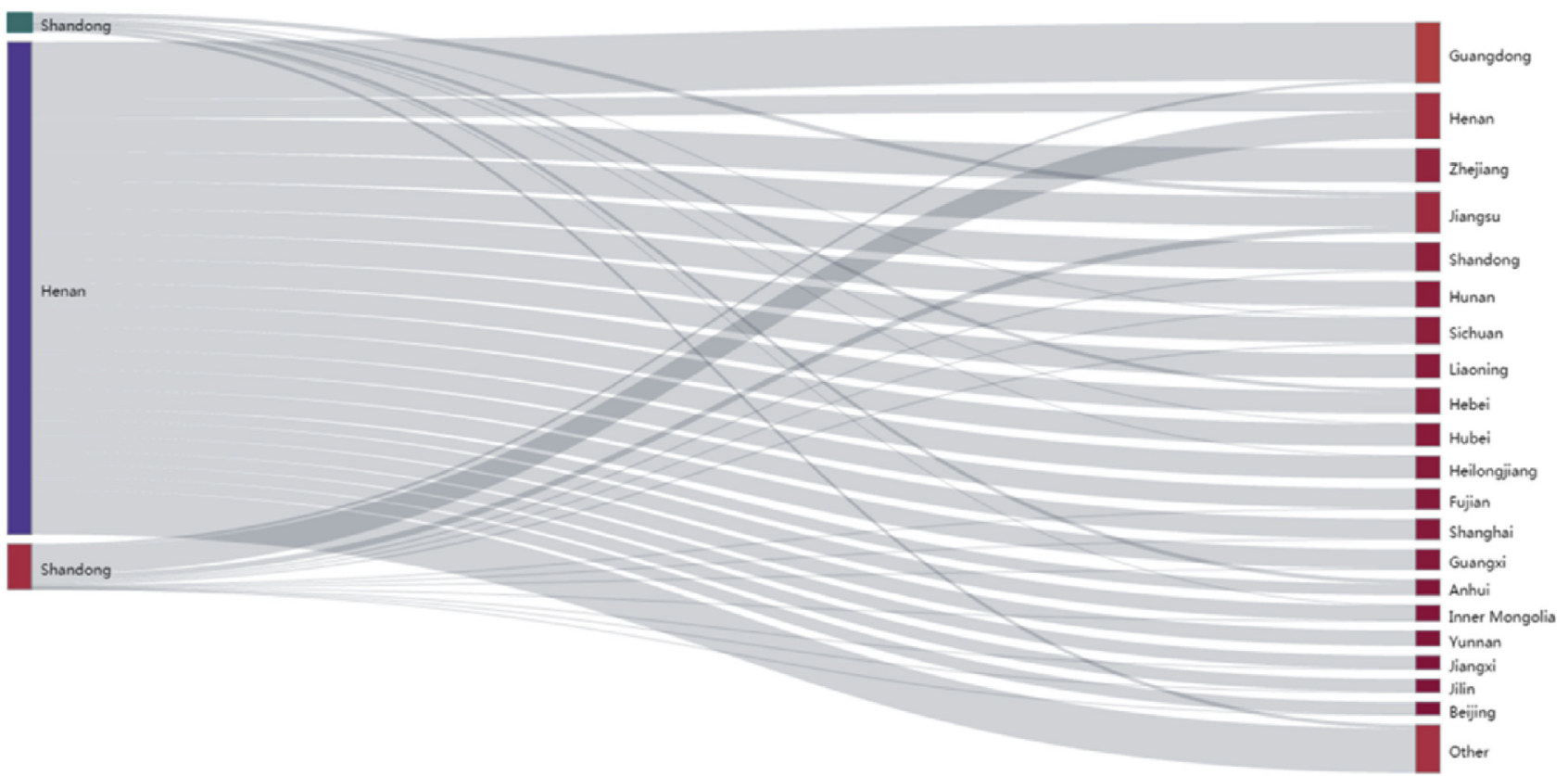

Fig. 6. Changes in the amount of wheat exported from Shandong and Henan provinces to other provinces under the MIX scenario (cf. the BAU scenario).

international agricultural trade into account. There is thus room to improve the TERM specification to fit the real world better. Despite the above caveat, the study showed the significant and relative impacts of variations in labor- and capital-augmenting technical change on wheat production in Shandong and Henan provinces and the effects on other provinces with respect to domestic wheat import and export volumes. Through comparisons between different scenarios, in Henan the increase in wheat yield under the MIX scenario is higher than the sum of the wheat yield increase for the CTC and LTC scenarios. This suggests that capital and labor are complementary influences on production when labor-augmenting technical change reaches a certain level. It also suggests that increasing labor- and capital-augmenting technical change simultaneously is more effective than increasing just one of the factors.

Under the LTC and MIX scenarios, the wheat yield decreased in Shandong province because there exists fierce competition in wheat production between Shandong and Henan province in the domestic market. However, because the market may not respond to the change in a timely fashion, the Chinese central government should provide rational top-down guidance, and adjust measures to local conditions. Each region should position itself based on establishing regional advantage, developing dominant industries, 
and improving competitive capacity. For example, the substantially increased amount of wheat production will satisfy the demand of the domestic market in Henan province under the LTC and MIX scenarios, and Shandong province may be able to develop other sectors of agricultural activity to effectively fulfill the reform from the supply side.

It is imperative to carry out reform from the supply side of agricultural production and to improve the quality and competitive advantage of grain production. With rising living standards, citizens are becoming increasingly concerned with the quality of agricultural products and with sustainable agricultural production and development (Gandhi and Zhou, 2014; Huang et al., 2015; Machlis, 2015). In this context, organic agriculture is of importance, but the yields given by organic agriculture are lower than those of traditional agricultural methods. Yields of organic agricultural production processes might be able to approximate the yields of traditional agriculture if suitable management systems were used. In addition, organic agriculture possesses important social, environmental, and economic benefits, and should be an important direction for agricultural development in the future (Seufert et al., 2012).

As suggested by previous studies (Fan et al., 2003; Huang et al., 2009), labor and capital are the two most important primary factors of production. For the 13 consecutive years from 2004 to 2016, the Chinese government has released thirteen "No 1 Central Documents" 3 focusing on agricultural and rural development and on the quality of farmers. In particular, in the last three years the "No 1 Central Documents" have been concerned with transforming the pattern of agricultural development and with agricultural modernization, especially with regard to increasing agricultural production via the mechanization and industrialization of agriculture. Moreover, in 2014, Premier Li Keqiang announced that the government must deal with three tasks: (i) Adjusting to the influx of 100 million people who have left agricultural work to settle in cities, (ii) providing accommodation in cities for 100 million people who formerly lived in urban shantytowns and villages, and (iii) guiding 100 million people into urbanization in the mid-west regions. Although these top-down policies have substantially promoted the development of agriculture, much remains to be explored with respect to improving agricultural production. Shandong and Henan both show a typical pattern of a large population with relatively small amounts of land, and in contrast, Northeast China has a typical pattern of large land area with relatively few people. In terms of agricultural development patterns, Shandong and Henan provinces could follow the Japanese agricultural model, developing biotechnology and high-precision agriculture to increase crop yields. Northeast China, in contrast, could follow the American agricultural model, adopting large-scale operations and using extensive mechanization.

With the development of the Chinese economy and the acceleration of urbanization, the cost of labor continues to rise (Lisha et al., 2013). Many scholars have argued whether the Lewis turning point of China's labor market has already been reached (Cai and Lu, 2013; Ge and Yang, 2011; Zhang et al., 2011). Whether or not this has occurred, the stage of labor supply surplus has already passed. Furthermore, farmers have increasingly switched to nonagricultural industries to obtain a competitive labor force market price (Deng et al., 2009). This situation has burdened the remaining rural population, in particular elderly people and children, who now constitute a greater proportion of the inhabitants of rural areas than before (Chang et al., 2011). This exodus has been partly

\footnotetext{
${ }^{3}$ No.1 Central Documents are the first documents published by China's central government every calendar year.
}

encouraged by the gap between rural and urban areas in the standard of living, and by the type of culture offered by urban areas. Previous studies have indicated that agricultural labor productivity in China has generally increased gradually (Li, 2013; Zhou and Cui, 2013), with the average annual growth rate of agricultural labor productivity being 5.57\% from 1978 to 2006 (Gao and Shi, 2009) and 17.4\% from 2004 to 2012 (Yang, 2014). Nevertheless, there remains a large gap between China and other developed countries; for instance, agricultural labor productivity in China in 2010 was about half of the world average level, $1 / 77$ th of the Japanese level, and 1/100th of the American level (Gao, 2015). Therefore, it is clearly necessary to improve labor productivity, develop new types of farmers with new skills, and improve the agricultural social service system. This may assist in achieving a smooth implementation of agricultural modernization.

Regarding agricultural capital stock in China, it is estimated that this amounted to 484.01 billion Chinese yuan in 2000 at the 1990 price, and that this stock rose to 1448.49 billion Chinese yuan by the end of 2011 at the 1990 price, a three-fold increase in about a decade (Luo, 2013). Not only has the central government adopted measures to support the development of agriculture, but also many companies have begun to enter the agricultural sector, for example, Lenovo, which is one of the biggest companies in China (Kuang, 2015). However, similar to the case for agricultural labor productivity, capital productivity in China is relatively low and there is still huge potential for capital productivity to increase (Gao, 2008; He, 2014).

As shown in the present study, changes in labor and capital productivity in grain production in Shandong and Henan will affect the production of grain in those provinces as well as the production and consumption of grain in other provinces. This reveals that dominant products in some regions possess a comparative advantage to some extent, and it is easy to dominate the domestic markets for particular commodities. American agriculture is divided into several specialized production areas based on natural conditions and regional advantages. These areas fully exert their advantage and improve the efficiency of their production. Such improvement in efficiency also improves these areas' competitive advantage in the international market. Rural China is entering a critical stage of restructuring, and therefore the national government should provide rational top-down guidance. Each region should position itself based on its identified regional advantage, thereby developing dominant industries and improving its competitive capacity. The national government should provide guidance to allow particular regions to develop their own competitive industries ( $\mathrm{Li}$ et al., 2015). If rural China can form different stable, sustainable, and specialized agricultural production areas, then this will not only guarantee China's food security, but will also improve the nation's competitive capacity in the international market.

\section{Conclusion}

In this study, we quantitatively analyzed the effect on imported and exported wheat volumes of other provinces and municipalities caused by increasing the labor and capital productivities of wheat production in Shandong and Henan Provinces through to 2020. We used The Enormous Regional Model to perform the analysis. The results show that an increase in capital productivity in Shandong and Henan provinces causes an increase in the volume of wheat imported by other regions from Shandong and Henan. When labor productivity in Henan and Shandong provinces is modeled to reach the level of Jiangsu, the net amount of wheat exported by Shandong province decreases, because of the substantial increase in labor productivity in Henan, and because there exists fierce competition 
in wheat production between Shandong province and Henan province in the domestic market. In contrast, the effect induced by the increase in labor productivity is much greater than the effect induced by the increase in capital productivity. Therefore, great importance should be attached not only to increasing capital technical change but also improving labor technical change, including gradually training rural workers to be involved in the more efficient agricultural production process envisaged for the future, thus contributing to the development of China's agricultural industry.

This study indicates that the regional competitive industry can shape absolute competition superiority, which consequently exerts a large impact on the homogeneity of products. Of the regions affected, the regions whose wheat trade with Shandong and Henan is tight and whose industrial structures are similar to those of Shandong and Henan provinces are the most substantially influenced. Therefore, the production of wheat in Shandong and Henan should keep up with the demand of the domestic market, thereby ensuring domestic food security, but should not cause a great impact on the domestic market due to overproduction, meaning that the interests of domestic rural workers can be protected.

Rural China is moving into a critical stage of restructuring, and therefore the government should provide rational top-down guidance. Each region should position itself based on establishing regional advantage, developing dominant industries and improving competitive capacity. The central government should avoid adopting a "one size fits all" policy, and simply supports a single industry or particular development patterns. The government should provide guidance and leadership based on regional advantages being established to develop competitive industries. Finally, rural China should form stable, sustainable, and specialized agricultural production areas/regions, which would not only guarantee China's food security, but also improve the nation's competitive capacity in the international market.

\section{Acknowledgement}

This research was supported by the National Natural Science Foundation of China (41501591), the key project of "135 plan" program of Institute of Geographical Sciences and Natural Resources Research, Chinese Academy of Sciences (2012ZD008), and Science and Technology Services (STS) program of Chinese Academy of Sciences (KFJ-EW-STS-058). The authors would like to thank the editor in chief, handling editor, and three anonymous reviewers for their constructive comments to lead an improved manuscript.

\section{References}

Acemoglu, D., 2000. Labor and Capital Augmenting Technical Change. National Bureau of Economic Research (working paper 7544).

Cai, F., Lu, Y., 2013. Population change and resulting slowdown in potential GDP growth in China. China World Econ. 21 (2), 1-14.

Chang, H.Q., Dong, X.Y., MacPhail, F., 2011. Labor migration and time use patterns of the left-behind children and elderly in rural China. World Dev. 39 (12), 2199-2210.

Chen, G., Liu, H., Zhang, J., Liu, P., Dong, S., 2012. Factors affecting summer maize yield under climate change in Shandong Province in the Huanghuaihai Region of China. Int. J. Biometeorol. 56 (4), 621-629.

De Brauw, A., Huang, J.K., Rozelle, S., Zhang, L.X., Zhang, Y.G., 2002. The evolution of China's rural labor markets during the reforms. J. Comp. Econ. 30 (2), 329-353.

Deng, X.Z., Huang, J.K., Scott, R., Uchida, E., 2009. Economic growth and the expansion of urban land in China. Urban. Stud. 47 (7), 813-843.

Fan, S.G., Zhang, X.,B., Robinson, S., 2003. Structural change and economic growth in China. Rev. Dev. Econ. 7 (3), 360-377.

General Administration of Customs of China (GACC), 2008. China Customs Statistics Yearbook. China Customs Press, Beijing.

Gandhi, V.P., Zhou, Z., 2014. Food demand and the food security challenge with rapid economic growth in the emerging economies of India and China. Food.
Res. Int. 63, 108-124.

Gao, F., Shi, L., 2009. The convergence of labor productivity growth in each province, China, from 1978 to 2006. Manag. World 149-160 (in Chinese).

Gao, F., 2008. Prior order for enhancing agricultural productivity and policy selection in China. Econ. Theory Bus. Manag. 812-819 (in Chinese).

Gao, F., 2015. International experience to improve agricultural productivity and China's choice. Fudan J. (Soc. Sci.) 1116-1124 (in Chinese).

Ge, S., Yang, D.T., 2011. Labor market developments in China: a neoclassical view. China Econ. Rev. 22 (4), 611-625.

He, Y., 2014. Problems and cause analysis of Chinese agricultural capital accumulation. Rural Econ. Sci. 25 (08), 33-36 (in Chinese).

Horridge, M., Madden, J., Wittwer, G., 2005. The impact of the 2002-2003 drought on Australia. J. Policy Model. 27 (3), 285-308.

Horridge, M., Wittwer, G., 2008. SinoTERM, a multi-regional CGE model of China. China Econ. Rev. 19 (4), 628-634.

Huang, J.K., Wu, Y.H., Rozelle, S., 2009. Moving off the farm and intensifying agricultural production in Shandong: a case study of rural labor market linkages in China. Agric. Econ. 40 (2), 203-218.

Huang, J., Yang, J., Deng, X., Wang, J., Rozelle, S., 2015. In: Urbanization, Food Production and Food Security in China, 2015 Allied Social Science Association (ASSA) Annual Meeting, January 3-5, 2015, Boston, Massachusetts. Agricultural and Applied Economics Association.

Huang, J.K., Xiang, C., Jia, X., Hu, R., 2012. Impacts of training on farmers' nitrogen use in maize production in Shandong, China. J. Soil Water Conserv. 67 (4), $321-327$.

Kennedy, J.J., 2007. From the tax-for-fee reform to the abolition of agricultural taxes: the impact on township governments in north-west China. China Quart. 189, 43-59.

Kuang, Y.P., 2015. Study on the Agricultural Capital Deepening in China. Issues in Agricultural Economy, pp. 1060-1068 (in Chinese).

Li, B., He, C., Hu, L., Li, Y., 2012. Dynamical analysis on influencing factors of grain production in Henan province based on grey systems theory. Grey Syst. Theory Appl. 2 (1), 45-53.

Li, Y.R., Long, H.L., Liu, Y.S., 2015. Spatio-temporal pattern of China's rural development: a rurality index perspective. J. Rural. Stud. 38, 12-26.

Li, J., 2013. Labor transfer, capital deepening and the improvement of agricultural labor productivity. J. Yunnan Univ. Finance Econ. 331-338 (in Chinese).

Lin, Y.Z., Deng, X.Z., Jin, Q.O., 2013. Economic effects of drought on agriculture in North China. Int. J. Disaster Risk Sci. 4 (2), 59-67.

Lisha, C., Yifan, S., Rasli, A.M., 2013. Correlation analysis on urbanization level and labor cost in China. Sains Humanika 64 (2).

Liu, Y.S., Lu, S.S., Chen, Y.F., 2013a. Spatio-temporal change of urban-rural equalized development patterns in China and its driving factors. J. Rural. Stud. 32, 320-330.

Liu, Y.S., Yang, R., Li, Y.H., 2013b. Potential of land consolidation of hollowed villages under different urbanization scenarios in China. J. Geogr. Sci. 23 (3), 503-512.

Liu, W.D., Liu, H.G., Fan, X.M., Chen, J., Tang, Z.P., 2012. Sector-specific spatial statistic model for estimating inter-regional trade flows: a case study of agricultural, chemical and electronic sectors in China. Acta Geogr. Sin. 62 (2), 147-156 (in Chinese).

Long, H.L., Woods, M., 2011. Rural restructuring under globalization in eastern coastal China: what can be learned from Wales. J. Rural Community Dev. 6 (1), 70-94.

Long, H.L., 2014. Land consolidation: an indispensable way of spatial restructuring in rural China. J. Geogr. Sci. 24 (2), 211-225.

Luo, H.X., 2013. Empirical Research on the Influence of Agricultural Capital Deepening on Chinese Agriculture Economic. Issues in Agricultural Economy, 94-14. (in Chinese).

Machlis, G.E., 2015. China addresses food and environment security. Science 347 (6224), 836-836.

Ministry of Agriculture of China (MAC), 2008. China Agriculture Yearbook. China Agriculture Press, Beijing.

National Bureau of Statistics of China (NBSC), 2008a. China Rural Statistical Yearbook. China Statistics Press, Beijing.

National Bureau of Statistics of China (NBSC), 2008b. China Statistical Yearbook. China Statistics Press, Beijing.

National Bureau of Statistics of China (NBSC), 2008c. China Yearbook of Agriculture Price Survey. China Statistics Press, Beijing.

National Bureau of Statistics of China (NBSC), 2008d. National Agricultural Products Data Compilation of Cost and Benefit. China Statistics Press, Beijing.

National Bureau of Statistics of China (NBSC), 2014. China Statistical Yearbook. China Statistics Press, Beijing.

Seufert, V., Ramankutty, N., Foley, J.A., 2012. Comparing the yields of organic and conventional agriculture. Nature 485 (7397), 229-232.

Song, Z., Storesletten, K., Zilibotti, F., 2011. Growing like china. Am. Econ. Rev. 101 (1), 196-233.

Tao, F., Zhang, Z., 2013. Climate change, wheat productivity and water use in the North China Plain: a new super-ensemble-based probabilistic projection. Agric. For. Meteorol. 170, 146-165.

Wittwer, G., 2012. Economic Modeling of Water: the Australian CGE Experience. Springer Science \& Business Media.

Wittwer, G., Horridge, M., 2010. Bringing regional detail to a CGE model using census data. Spat. Econ. Anal. 5 (2), 229-255. 
Xue, W., 2012. A theoretical explanation of agricultural capital and its formation: from the perspective of economic growth and capital agglomeration. Rural Econ. 861-865 (in Chinese).

Yang, Z.C., 2014. 9.Seeing the coordinated development of industrialization, urbanization and agricultural modernization from the law of development of the industry labor productivity. Sci. Mosaic 183-189 (in Chinese).
Zhang, X., Yang, J., Wang, S., 2011. China has reached the Lewis turning point. China Econ. Rev. 22 (4), 542-554.

Zhou, P., Cui, W.F., 2013. China major grain producing areas of agricultural labor productivity growth path analysis. Chin. Agric. Sci. Bull. 29 (32), 112-117 (in Chinese). 